\title{
Efficacy of egg yolk and nitroglycerin ointment as treatments for acute anal fissures: A randomized clinical trial study
}

\author{
Masoumeh Salari ${ }^{1}$, Roshanak Salari ${ }^{2}$, Maliheh Dadgarmoghadam ${ }^{3}$, Majid Khadem-Rezaiyan ${ }^{4}$, Mousalreza \\ Hosseini $^{5}$
}

${ }^{1}$ M.D., Internist, Assistant Professor, Ghaem Hospital, Faculty of Medicine, Mashhad University of Medical Sciences, Mashhad, Iran

${ }^{2}$ Ph.D. of Drug Control, Assistant Professor, Department of Traditional Persian Pharmacy, School of Persian and Complementary Medicine, Mashhad University of Medical Sciences, Mashhad, Iran

${ }^{3}$ M.D., Assistant Professor, Department of Community Medicine, Faculty of Medicine, Mashhad University of Medical Sciences, Mashhad, Iran

${ }^{4}$ M.D., Community Medicine Specialist, Department of Community Medicine, Faculty of Medicine, Mashhad University of Medical Sciences, Mashhad, Iran

${ }^{5}$ M.D., Gastroenterologist, Assistant Professor, Ghaem Hospital, Faculty of Medicine, Mashhad University of Medical Sciences, Mashhad, Iran

\section{Type of article: Original}

\begin{abstract}
Background: Acute anal fissure as a common disease in society has several etiologies and manifestations such as severe anal pain and bleeding. Nitroglycerin ointment $0.2 \%$ is the most common topical treatment used. The most common side effect of nitroglycerin is headache, which is annoying for patients and often leads to discontinuation of the drug.

Objective: Comparison of egg yolk as a natural substance with analgesic and anti-inflammatory properties and minimal side effects with nitroglycerin ointment in the treatment of acute anal fissure.

Methods: This randomized clinical trial was carried out during a 10-day period in the Gastroenterology clinic of Ghaem Hospital, Mashhad, Iran (year 2015). 126 patients who filled the inclusion criteria were enrolled. The patients were randomly divided into two groups. Nitroglycerin ointment $(0.2 \%)$ was applied by patients in the first group, twice daily for 10 days. For the second group, one egg yolk once a day was administered rectally up to 10 days. The pain and bleeding severity were recorded every two days up to 10 days after finishing the treatment course, based on visual scale

Results: The results showed that egg yolk caused a significant reduction in pain and bleeding compared with nitroglycerin $(\mathrm{p}<0.05)$. At the beginning of the study, the difference in pain intensity between the two groups was not statistically significant ( $\mathrm{p}$-value $=0.25$ ). However, it became significant in the following days. Changes in the frequency of rectorrhagia were also significant in both groups, showing a major decrease in the number of rectorrhagia cases $(\mathrm{p}<0.001)$.

Conclusion: Egg yolk is more efficient than nitroglycerin in the treatment of acute anal fissure. In addition, lack of any side effects results in the completion of the treatment course by the patients.

Trial Registration: The trial was registered at the Iranian Registry of Clinical Trials (http://www.irct.ir) with the Irct ID: IRCT2015050718915N3.

Funding: This work was supported by a grant from the Vice Chancellor of Research of Mashhad University of Medical Sciences.

Keywords: Anal fissure, Egg yolk, Nitroglycerin, Headache

\section{Corresponding author:}

Assistant Professor Dr., Mousalreza Hosseini, Ghaem Hospital, Faculty of Medicine, Mashhad University of Medical Sciences, Mashhad, Iran. Tel: +98.5138012742, Email: dr.hosseinimr@gmail.com

Received: May 06, 2016, Accepted: August 13, 2016, Published: October 2016

iThenticate screening: August 02, 2016, English editing: August 25, 2016, Quality control: September 04, 2016

(C) 2016 The Authors. This is an open access article under the terms of the Creative Commons Attribution-NonCommercialNoDerivs License, which permits use and distribution in any medium, provided the original work is properly cited, the use is non-commercial and no modifications or adaptations are made.
\end{abstract}




\section{Introduction}

Anal fissure is known as a break in the skin of the anal canal $(1,2)$. It affects people of all ages and gender, whereas around $50 \%$ of people in the age range of 20 to 50 have experienced fissure symptoms at least once in their lifetime. The prevalence of fissures in women increases during pregnancy $(3,4)$. Hard stools, long-term diarrhea, and constipation, which affect blood flow to the anal area, can cause fissures in adults. Many factors and mechanisms have been proposed as the etiology for non-healing fissures, yet the most important is anal mucosa impaired blood flow due to the spamming of the anal sphincter (5). Based on the type of fissure, different symptoms may be present such as pain and bleeding around the anal area. In acute anal fissures, rectal bleeding with severe pain and swelling around the anus occurs. Most anal fissures are not limited to the anal opening and may extend to other anal areas. In addition, the depth of fissure varies from superficial to those that happen in the sphincter muscle. In the less advanced stages of fissures, the initial treatment is hydration, which consists of various types of fluids or fiber intake. Administration of NSAIDs also can reduce the pain. Besides, different topical agents are used for its treatment. In severe cases, which do not respond to these therapeutic methods, surgery is required (6-8). One of the common topical drug forms, which are available for the treatment of moderate to severe pain caused by anal fissure, is nitroglycerin ointment $(0.2 \%)$. It belongs to the nitrate group medications and applies its effect by relaxing the blood vessels. However, certain side effects in different patients have led to discontinuation of this kind of therapy. Among its minor side effects, headaches, dizziness, and faintness are notable. In severe cases, patients may suffer from severe headaches and various allergic reactions such as itching; swelling of the lips, throat, or tongue; and difficulty in breathing (9). Furthermore, in acute stages of the fissure, nitroglycerin is not potent enough to relieve the pain. According to traditional Chinese medicine, balance in body energy is believed to result in good health in human beings. Chinese medicine also has categorized food into different classifications such as hot, cold, and neutral. Both the hot and cold groups disturb the body energy balance while the neutral, such as egg yolk, have a less negative impact. Egg yolk also has shown beneficial effects on the heart and kidneys and also stomach by reducing acids and toxins (10). The yolk is a part of an egg, which feeds the embryo. It contains water, carbohydrates, fats (oleic acid, linoleic acid, linolenic acid, palmitoleic acid, stearic acid, myristic acid, and palmitic acid), proteins (tryptophan, threonine, isoleucine, leucine, lysine, histidine, valine, alanine, tyrosine, phenylalanine, glycine, aspartic acid, arginine, glutamic acid, proline and serine), vitamins (A, D, E, K, B1, B2, B5, and B9), minerals (calcium, zinc, potassium, magnesium, phosphorus, and iron), and cholesterol. Traditionally in Iran, people believed that egg yolk oil, which is extracted by direct heat possesses, has analgesic and anti-inflammatory properties (11), yet its mechanism as an anti-inflammatory agent is unclear. A study by Shen Q. et al. claimed that egg yolk affects the NF- $\mathrm{KB}$ level in the inflammatory procedure, which is a major regulator in the transcription pathway (12). Following a partial delipidation process, egg yolk composition includes polar and nonpolar fractions. Polar lipids extracted from egg yolk, lipophilic vitamins, and water soluble proteins inhibit the inflammatory pathways. This means that the inflammation and oxidative stress pathways are disturbed by vitamins, carotenoids, and polar phospholipids of egg yolk. Besides, the cholesterol and polyunsaturated fatty acids content of egg yolk suppress the pro-inflammation pathways. In fact, the activation of NF- $\mathrm{kB}$ (a key regulator of acute and chronic inflammation) is affected by egg yolk ingredients (12). Hence, egg yolk could be defined as an appropriate drug choice in the treatment of an anal fissure. Due to the aforementioned facts, patients usually refuse to thoroughly follow and complete the routine treatment course. Therefore, a type of natural substance such as egg yolk is needed, which has high enough efficacy and minimal harmful side effects in anal fissures. The aim of this study was to compare the efficacy of egg yolk and nitroglycerin ointment in the treatment of acute anal fissures.

\section{Material and Methods}

\subsection{Trial design and participants}

This randomized clinical trial was carried out during a 10-day period (year 2015). This clinical trial was conducted in Ghaem Hospital (Gasteroenterology Department). Ghaem Hospital is one of the main hospitals in Mashhad, Iran, and it is affiliated with Mashhad University of Medical Sciences. The research population was comprised of patients, referred to the Gastroenterology Clinic of Ghaem Hospital, with acute anal pain with and without rectorrhagia diagnosed by a gastroenterologist as an acute fissure. Due to ruling out other underlying conditions, patients who had rectorhalgia were given a colonoscopy.

\subsection{Selection criteria}

Patients with acute anal pain with or without rectorrhagia and painful defecation diagnosed by a single gastroenterologist as an acute anal fissure were enrolled in this study. Diagnosis of an anal fissure was performed after taking patient history and physical examination. Patients with atypical anal fissures (e.g., lateral, anterior anal 
fissures, known as underlying diseases such as Crohn's disease, hemorrhoids, and pregnant or lactating women) were excluded from the study.

\subsection{Interventions}

A laxative agent was given to both groups, and all patients were asked to sit in a tub of warm water for 30 minutes daily. The laxative agent prescribed was Lactolose syrup $(10 \mathrm{~g} / 15 \mathrm{ml})$, a product of Alborz Daru. It was administered in all participants up to softening of the stool (about $5 \mathrm{ml}$ twice a day). Nitroglycerin ointment $(0.2 \%)$ was manufactured by Troikaa Parenterals Pvt. Ltd and applied by patients in the first group, twice daily for 10 days around the anus and $1 \mathrm{~cm}$ inside by ear pick. For the second group, one egg yolk once a day was administered rectally up to 10 days. To avoid feeling pain in patients, egg yolk was entered about $1 \mathrm{~cm}$ into the anal canal by the narrow head of a syringe. The protocol of pulling egg yolks into the syringe and its entry into anal canal was taught to the patients. The pain and bleeding severity were recorded every two days up to 10-day follow-ups after finishing the 10-day treatment course, based on a visual scale.

\subsection{Outcomes}

The primary outcomes of our analyses were investigating the changes in severity of pain and bleeding in an acute anal fissure. Also, the secondary outcome from the analyses was the adverse effects of the egg yolk during the course of treatment.

\subsection{Sample size}

This study was done according to census method, and 126 subjects was enrolled in this study. After the completion of the study, we calculate the power of the study with power and sample size program. The Type I error probability associated with the test of this null hypothesis is 0.05 . If the true difference in the experimental and control means is 4.04 , we will be able to reject the null hypothesis that the population means of the experimental and control groups are equal with probability (power) $90 \%$.

\subsection{Randomization and blinding}

This was a randomized clinical trial study. The patients were randomly (based on random number table) divided into two groups. Pain and bleeding severity were recorded every two days up to 10 days, based on visual scale, by another person who was blind to the allocations. Both assessor and the statistician were unaware of the allocations, and allocation concealment was kept until the end of the study. It also was explained to patients that they were in two different treatment groups, but they did not know about the treatments, so they were also blind. The results were recorded in a specially designed checklist by a physician. After being allocated randomly to the groups, all participants were referred to the hospital's pharmacy to get their drugs.

\subsection{Statistical methods}

The collected data were analyzed by SPSS version 22 statistical software. Description of data based on their distribution was performed by statistical parameters. The analytical tests applied in this study included independent t-test, repeated measures of ANOVA, Mann-Whitney U test, and the Cochran's Q test. The significance level was set at $\mathrm{p}<0.05$.

\subsection{Research ethics}

This proposal was presented to the Ethics Committee of Mashhad University of Medical Sciences after its scientific approval by the Gasteroenterology Department. The Ethics Committee approved the study with the number of IR.MUMS.REC.1393.51. This study also was registered in the Iranian Registry of Clinical Trials (irct.ir) with the ID: IRCT2015050718915N3. The authors confirm that all ongoing and related trials for this drug/intervention are registered. Indeed, in this study, for ethical considerations, the participants were informed about the objective and nature of the study, and each participant provided her written consent in her native language (Persian) prior to the study. The patients could have left the research whenever they wanted. Also, we were committed to keeping all of the participants' information confidential.

\section{Results}

The CONSORT flow diagram of this clinical trial is shown in Figure 1. Of the 154 patients referred to the Gastroenterology Clinic, 126 patients who filled the inclusion criteria were enrolled. These patients were studied and divided into two groups (group $1=62$ patients; group $2=64$ patients) with an average age of $32.30 \pm 8.90$ years. The patients' average age and their sex distribution was not significantly different between the two groups $(\mathrm{p}=0.31$; 
$\mathrm{p}=0.8$ ). Rectorrhagia frequency was seen in 53 patients in the first group and in 50 patients in the second group. In the first group, nitroglycerin ointment was administered to cure the acute anal fissures; in the second group, egg yolk was used. No drops-out or drops-in were observed during the study. The mean pain scores at different time points after a 10-day course of treatment (first visit and second day up to tenth day follow-up visits) are presented in Table 1. At the beginning of the study, the difference in pain intensity between the two groups was not statistically significant ( $\mathrm{p}$-value $=0.25$ ). However, it became significant in the following days. The changes during the study course in both groups were meaningful. The mean reduction changes in pain score decreased with time (Figure 2).

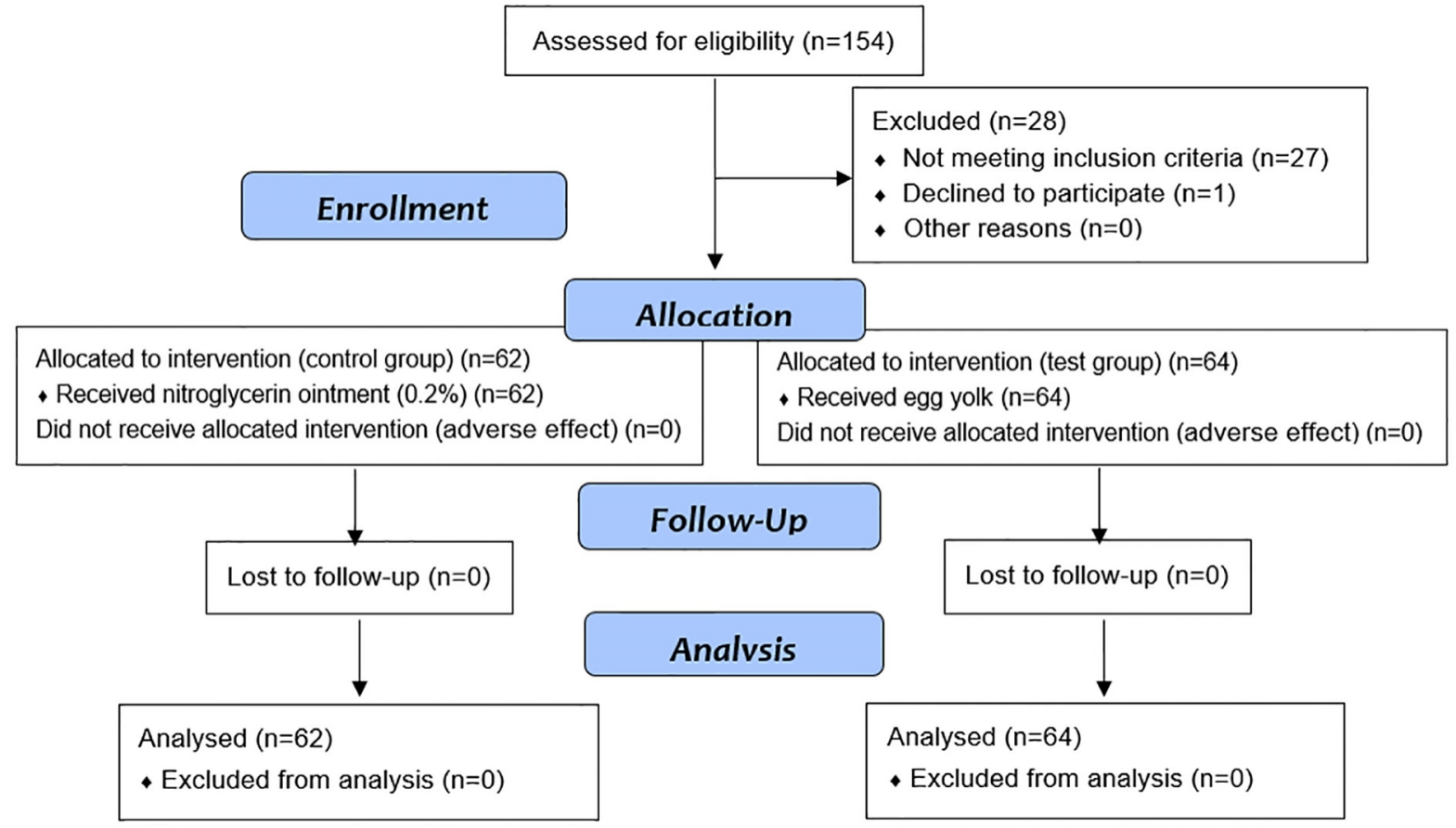

Figure 1. CONSORT flow diagram of the trial

Table 1. Mean pain scores at different studied time points

\begin{tabular}{|l|l|l|l|l|l|l|l|}
\hline Time & 1st visit after 10 days & 2nd day & 4th day & 6th day & 8 th day & 10th day & p-value \\
\hline $\begin{array}{l}\text { Nitroglycerin } \\
\text { group }\end{array}$ & $9.48 \pm 0.9$ & $9.31 \pm$ & $8.98 \pm$ & $7.92 \pm$ & $6.31 \pm$ & $4.94 \pm$ & $<0.01$ \\
\hline $\begin{array}{l}\text { Egg yolk } \\
\text { group }\end{array}$ & $9.28 \pm 1$ & 1.15 & 1.29 & 1.90 & 2.80 & 3.76 & \\
\hline$p$-value & & $2.45 \pm$ & $3.13 \pm$ & $1.73 \pm$ & $0.92 \pm$ & $0.88 \pm$ & $<0.01$ \\
\hline
\end{tabular}

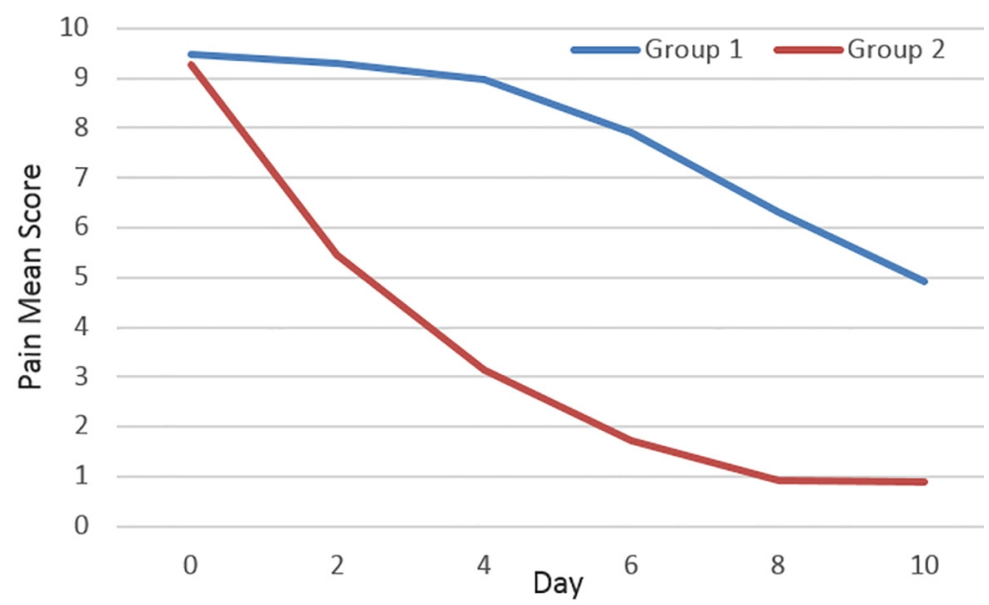

Figure 2. Pain score during the study period 
The maximum changes between two consecutive follow-ups was between the sixth and eighth day follow-up for the first group; in the second group, this was observed between the first visit and the second day follow-up visits. Changes in the frequency of rectorrhagia were also significant in both groups showing a major decrease in the number of rectorrhagia cases $(\mathrm{p}<0.001)$ (Figure 3); whereas the pace of decline was higher in the egg yolk group. Studying the fissure's grade at the end of the third-day follow-up showed a significant higher mean rank grade in group 1 (83.67) compared with group 2 (43.96) $(\mathrm{p}<0.001)$.

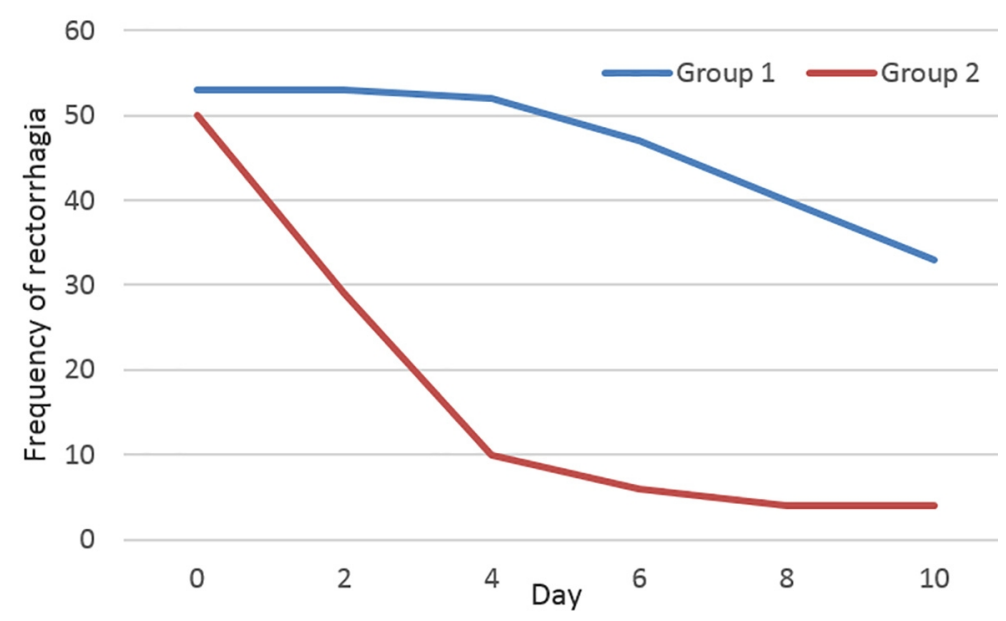

Figure 3. Changes in frequency of rectorrhagia in two groups during the study course

\section{Discussion}

Nowadays anal fissure disease is common in different societies. Superficial fissures usually heal spontaneously, whereas other types of fissures become deep and chronic, ultimately resulting in an infection $(13,14)$. The occurrence of anal fissure below the age of 30 is rare. In this study, the patients' average age was $32.30 \pm 8.90$ ranging from 35 to 40 years. This fact highlights a social and cultural aspect for this disease, indicating that lifestyle plays an important role in the occurrence of anal fissures. The available common topical treatments such as nitroglycerin ointment, which is used in anal fissures, usually relax the sphincter muscle. However, side effects such as severe headaches limit its administration. In the next stage, calcium channel blockers and topical diltiazem were introduced to cure anal fissures. These drugs also have their own side effects (15-19). Therefore, the use of a natural agent capable of improving the healing process without causing side effects is highly anticipated. The purpose of this study was the introduction of egg yolk as an effective treatment for anal fissures. Egg yolk is a natural and efficient substance with no side effects. The anti-inflammatory properties of egg yolk originate from some lipid fractions, which suppress NF- $\mathrm{kB}$ in the inflammatory process. Therefore, its use is highly desirable for such patients. Some factors have been proposed to accelerate the development of anal fissures including nutrition, genetics, drugs, and occupation $(3,20)$. Moreover, parameters such as pregnancy and low physical activity put women at a greater risk compared with men. In general, rectal bleeding is the most important symptom that causes the patient to seek medical help. Many methods have already been studied in the treatment of an anal fissure; in this study, nitroglycerin ointment, which is a common medication for this condition, was compared with egg yolk as a potent natural medicine. Since the course of this disease is around 10 days, pain scores were studied in both groups every two days up to the tenth day. In the first follow-up visit (after 10 days of therapy), no significant difference was observed in two groups of patients having received two different treatments. But, a day later, patients who had received egg yolk experienced significantly less pain in comparison with the other group. On the tenth day, the pain score in the egg yolk group of patients almost reached to zero (Table 1). These results confirm the analgesic effects and anti-inflammatory properties of egg yolk in comparison with nitroglycerin ointment. In addition, egg yolk reduced pain more rapidly than nitroglycerin ointment. The highest pain reduction changes in the group receiving the egg yolk occurred on the second day; in the other group, it was recorded on the eighth day (Figure 2). Egg yolk not only reduced pain to zero but also had a significantly faster pain relief course, which was followed by higher patient satisfaction. In general, almost $52 \%$ of individuals who take nitroglycerin ointment experience severe headache, which is an undesirable side effect for patients. Interestingly, this side effect was not seen when egg yolk was used. Nevertheless, both methods significantly reduced the frequency of rectorrhagia as the most important manifestation of the disease $(p<0.001)$ (Figure 3). Egg yolk affected rectorrhagia more rapidly and efficiently than the other therapeutic methods. According to what has been said, egg yolk as a natural analgesic and anti- 
inflammatory agent can cure an acute anal fissure more efficiently than nitroglycerin ointment. Not only does it heal the anal fissures better but also it acts more rapidly. Therefore, it can be used as an alternative treatment without any side effects. Our study had some limitations. It was limited to the treatment of acute anal fissures, so we cannot generalize our findings to all types of anal fissures. Also, we had no neutral placebo group, which could have provided more detailed information. The reason was that we did not want to prevent the patients to consume common treatments; further, our main objective was to compare the efficacy of different drugs in the treatment of this disease.

\section{Conclusions}

In this study, the findings represent egg yolk effectiveness in the treatment of acute anal fissures even better than nitroglycerin ointment. According to the high prevalence of this disease and the awful side effects of common treatments, egg yolk as a kind of natural way of treatment could be beneficial. We suggest to work on the efficacy of egg yolk on other types of anal fissures. Of course, more clinical trials must be done to confirm the efficacy of egg yolk in anal fissures.

\section{Acknowledgments:}

This work was supported by a grant from Ghaem Hospital and the Vice Chancellor of Research of Mashhad University of Medical Sciences.

\section{Trial Registration:}

The trial was registered at the Iranian Registry of Clinical Trials (http://www.irct.ir) with the Irct ID: IRCT2015050718915N3.

\section{Funding:}

This work was supported by a grant from the Vice Chancellor of Research of Mashhad University of Medical Sciences.

\section{Conflict of Interest:}

There is no conflict of interest to be declared.

\section{Authors' contributions:}

All authors contributed to this project and article equally. All authors read and approved the final manuscript.

\section{References:}

1) Lund JN, Scholefield JH. Aetiology and treatment of anal fissure. Br J Surg. 1996; 83(10): 1335-44. doi: 10.1002/bjs.1800831006. PMID: 8944447.

2) Van Outryve M. Physiopathology of the anal fissure. Acta Chir Belg. 2006; 106(5): 517-8. doi: 10.1080/00015458.2006.11679942. PMID: 17168260.

3) Blagodarnij LA. Treatment of chronic anal fissure. Rus Med J. 2002; 10: 1327-30.

4) Kirsch J. Anal fissure. Wien Med Wochenschr. 2004; 154(3-4): 69-72. doi: 10.1007/s10354-004-0038-3. PMID: 15038578 .

5) Collins EE, Lund JN. A Review of Chronic Anal Fissure Management. Tech Coloproctol. 2007; 11(3): 209-23. PMID: 17676270. doi: 10.1007/s10151-007-0355-9.

6) Schubert MC, Sridhar S, Schade RR, Wexner SD. What every gastroenterologist needs to know about common anorectal disorders. World J Gastroenterol. 2009; 15(26): 3201-9. doi: 10.3748/wjg.15.3201. PMID: 19598294, PMCID: PMC2710774.

7) Zbar AP, Aslam M, Allgar V. Faecal incontinence after internal sphincterotomy for anal fissure. Tech Coloproctol. 2000; 4(1): 25-8. doi: 10.1007/s101510050050.

8) Lund JN. Nitric oxide deficiency in the internal anal sphincter of patients with chronic anal fissure. Int J Colorectal Dis. 2006; 21(7): 673-5. doi: 10.1007/s00384-005-0757-y. PMID: 16052310.

9) Azarnoff DL, Lee JC, Lee C, Chandler J, Karlin D. Quality of extemporaneously compounded nitroglycerin ointment. Dis Colon Rectum. 2007; 50(4): 509-16. doi: 10.1007/s10350-006-0818-5. PMID: 17476559.

10) Chinese Herbs: Chicken Egg Yolk. Posted on July 30, 2013 by Acupuncture Associates Wilmington. 
11) Mahmoudi M, Ebrahimzadeh MA, Pourmorad F, Rezaie N, Mahmoudi MA. Anti-inflammatory and analgesic effects of egg yolk: a comparison between organic and machine made. Eur Rev Med Pharmacol Sci. 2013; 17(4): 472-6. PMID: 23467945.

12) Shen Q, Riedl KM, Cole RM, Lehman C, Xu L, Alder H, et al. Egg Yolks Inhibit Activation of NF- $\kappa B$ and Expression of Its Target Genes in Adipocytes after Partial Delipidation. J Agric Food Chem. 2015; 63(7): 2013-25. doi: 10.1021/jf5056584. PMID: 25620076, PMCID: PMC4362627.

13) Kennedy ML, Sowter S, Nguyen H, Lubowski DZ. Glyceryl trinitrate ointment for the treatment of chronic anal fissure: results of a placebo controlled trial and long-term follow-up. Dis Colon Rectum. 1999; 42(8): 1000-6. doi: 10.1007/BF02236691. PMID: 10458121.

14) Watson SJ, Kamm MA, Nicholls RJ, Phillips RK. Topical Glyceryl Trinitrate in the Treatment of Chronic Anal Fissure. Brit J Surg. 1996; 83(6): 771-5. doi: 10.1002/bjs.1800830614. PMID: 8696736.

15) Simpson J, Lund JN, Thompson RJ, Kapila L, Scholefield JH. The Use of Glyceryl Trinitrate (GTN) in the Treatment of Chronic Anal Fissure in Children. Med Sci Monitor. 2003; 9(10): 123-6. PMID: 14523338.

16) Lund JN, Scholefield JH. A Randomised, Prospective, Double-blind, Placebo-controlled trial of Glyceryl Trinitrate Ointment in Treatment of Anal Fissure. Lancet. 1997; 349(9044): 11-4. doi: 10.1016/S01406736(96)06090-4. PMID: 8988115.

17) Utzig MJ, Kroesen AJ, Buhr HJ. Concepts in pathogenesis and treatment of chronic anal fissure-a review of the literature. Am J Gastroenterol. 2003; 98(5): 968-74. doi: 10.1111/j.1572-0241.2003.07423.x. PMID: 12809816.

18) Bailey HR, Beck DE, Billingham RP, Binderow SR, Gottesman L, Hull TL, et al. A study to determine the nitroglycerin ointment dose and dosing interval that best promote the healing of chronic anal fissures. Dis Colon Rectum. 2002; 45(9): 1192-9. doi: 10.1097/01.DCR.0000027060.14159.6E. PMID: 12352236.

19) Bulus H, Varol N, Tas A, Coskun A. Comparison of topical isosorbide mononitrate, topical diltiazem, and their combination in the treatment of chronic anal fissure. Asian J Surg. 2013; 36(4): 165-9. doi: 10.1016/j.asjsur.2013.01.010. PMID: 24054756.

20) Yousefi M, Mahdavi MR, Hosseini SM, Bahrami A, Davati A, Kamalinejad M, et al. Clinical Evaluation of Commiphora Mukul, a Botanical resin, in the Management of Hemorrhoids: A randomized controlled trial. Pharmacogn Mag. 2013; 9(36): 350-6. doi: 10.4103/0973-1296.117832. PMID: 24124288, PMCID: PMC3793341. 